\title{
Dual Coronary Artery Fistula from Left Anterior Descending and Right Coronary Artery to Pulmonary Trunk in a Patient with Myocardial Infarction-A Case Report
}

\author{
Animesh Mishra, Tony Ete, Rinchin Dorjee, Pravin Kumar Jha, Amit Malviya, Gaurav Kavi \\ Department of Cardiology, North Eastern Indira Gandhi Regional Institute of Health and Medical Sciences, \\ Shillong, India \\ Email: tonyete14@gmail.com
}

Received 21 March 2016; accepted 25 July 2016; published 28 July 2016

Copyright (C) 2016 by authors and OALib.

This work is licensed under the Creative Commons Attribution International License (CC BY). http://creativecommons.org/licenses/by/4.0/

(c) $\underset{\mathrm{EY}}{\text { (i) Open Access }}$

\section{Abstract}

Coronary artery fistulas (CAF) are precapillary communications between a coronary artery and a cardiac chamber or vessel. CAF have been described as the most common hemodynamically significant congenital coronary anomal. However, it remains a relatively uncommon clinical problem. Coronary fistulas originates slightly more common from the right than from the left coronary artery, but the bilateral fistulas-those that originate from both coronary arteries-accounts for only $5 \%$ of total cases. These bilateral fistulas have a unique tendency to terminate in the pulmonary artery. More than half of the bilateral and only $17 \%$ of unilateral fistulas, terminates in this manner [1]. CAF are believed to be embryological remnants of sinusoidal connections between the lumens of the primitive tubular heart. This was first described by Maude Abbott in 1908 [2]. These fistulas are usually discovered incidentally upon coronary angiography [3]. Their incidence in the overall population is reported about $0.002 \%$ and constitutes $0.13 \%$ of congenital cardiac lesion, however, they are found in $\mathbf{0 . 0 5 \%}$ to $0.25 \%$ of patients who undergo coronary angiography. The most common site of drainage is the right ventricle seen in $41 \%$ of patients. Congenital CAFs usually result from abnormal embryological development of the myocardial vascular system. Acquired CAFs are seen after trauma, endovascular procedures like coronary angiography, endomyocardial biopsy etcor cardiac transplantation. True fistulas of the circulatory system are characterized by an ectatic vascular segment that shows aberrant flow connecting two vascular territories governed by large pressure differences. We report a case of double coronary to pulmonary artery fistula discovered during emergent coronary angiography for acute inferior wall ST-elevation myocardial infarction (STEMI) in a patient with no prior cardiac symptoms.

\section{Keywords}

Myocardial Infarction, Coronary Artery Fistula, Pulmonary Artery

How to cite this paper: Mishra, A., Ete, T., Dorjee, R., Jha, P.K., Malviya, A. and Kavi, G. (2016) Dual Coronary Artery Fistula from Left Anterior Descending and Right Coronary Artery to Pulmonary Trunk in a Patient with Myocardial Infarction-A Case Report. Open Access Library Journal, 3: e2590. http://dx.doi.org/10.4236/oalib.1102590 


\section{Subject Areas: Cardiology}

\section{Case}

A 48-year-old man presented with acute onset chest pain in emergency. Electrocardiogram revealed ST segment elevation of $>2 \mathrm{~mm}$ in leads II, III, aVF. Blood for troponin T was positive. The patient was diagnosed as a case of ST segment elevation inferior wall myocardial infarction. Dual Antiplatelets were started with other supporting measures and the patient was transferred immediately to the catheterization laboratory. Coronary angiography showed significant stenoses of the left anterior descending (LAD), left circumflex (LCX) arteries and borderline lesion in mid right coronary artery (RCA). Moreover, it revealed the presence of 2 large coronary artery fistulas (CAF), one originating from distal part of left circumflex artery (Figure 1) and the other from proximal part of right coronary artery (Figure 2), both draining into the pulmonary trunk at 2 different, but close, entry

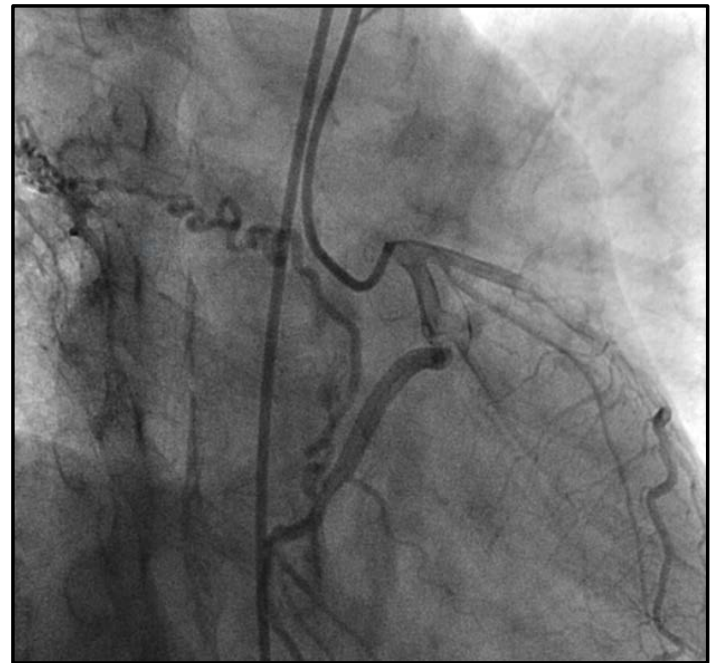

Figure 1. Right Anterior oblique caudal view showing fistula from left anterior descending artery to pulmonary artery.

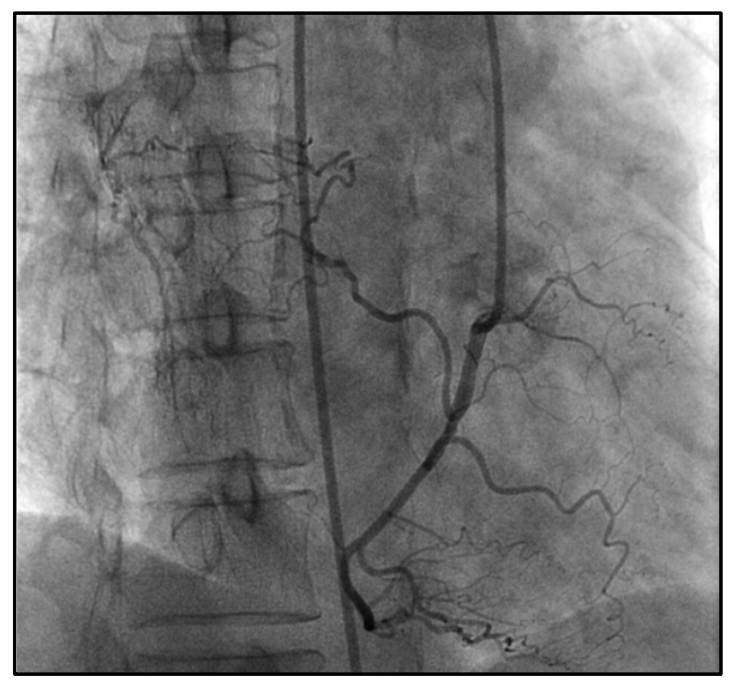

Figure 2. Right anterior oblique view showing fistula from right coronary artery to pulmonary artery. 
sites. Blood tests revealed $\mathrm{Hb}-12 \mathrm{gm} / \mathrm{dl}$, total leucocyte count $-13,800 / \mathrm{cumm}$, platelet count -4.5 lakhs and creatine kinase levels of $1500 \mathrm{U} / \mathrm{L}$ along with elevation of CK-MB fraction. Renal function test and liver function test were within normal limit. Transthoracic echocardiography (TTE) showed an ejection fraction of $45 \%$, hypokinesia in LAD territory, normal cardiac chamber dimensions and delayed relaxation abnormality with no evidence of pulmonary hypertension. After consideration of anatomy and extension of the remaining coronary stenoses and according to the wishes of the patient, the surgical treatment option (coronary bypass grafting and fistula ligation) was chosen. The clinical evolution was uneventful, and the patient was discharged on dual-antiplatelet therapy. He was on dual antiplatelets as in acute coronary syndrome it has a class 1 recommendation (Level of evidence A). Following discontinuation of dual-antiplatelet, the patient underwent coronary bypass grafting procedure for the LAD and LCX stenoses. A sequential LIMA (left internal mammary artery) grafting to LAD followed by LCX and ligation of the coronary artery fistulas at the ostium at the origin on the pulmonary artery was done after 6 weeks. The CABG was carried out on pump. No complications were observed in the post-operative phase and the patient was discharged 10 days after surgery to join a rehabilitation program.

\section{Discussion}

The incidence of coronary artery fistula in coronary angiogram has been reported to be $0.2 \%$. Coronary artery fistula (CAF) originates from the right coronary artery in $15 \%$ of cases, from the left coronary artery in 53\%, from both coronary arteries in 7\% [4]. Fistula between coronary artery and pulmonary artery is a rare congenital anomaly first described by Krause in 1865. First successful surgical treatment of CAF was described by Fell and colleagues in 1958 [5]. Coronary artery fistula (CAF) can be congenital or acquired. The majority of CAFs reported are of the congenital form. Acquired CAF has rarely been discussed. There is no race or sex predilection for CAF. Bilateral coronary artery-pulmonary artery fistulas, however, are a distinct entity. In contrast with unilateral coronary artery fistulas, of which only $17 \%$ terminate in the pulmonary artery, $56 \%$ of the reported bilateral fistulas have their termination in pulmonary artery [4]. Most of the fistulas of coronary artery arise by failure of intramyocardial sinusoids to obliterate, so bilateral involvement requires independent developmental errors at two separate sites. However, fistulas to the pulmonary artery probably arise by supernumerary implantation of developing coronary arteries into pulmonary arterial portion of the embryonic truncusarteriosus. This bilateral involvement is thus facilitated by proximity of both coronary arteries to the truncus. Anomalous origin of the left or right coronary artery from the pulmonary artery can be explained by this defect in embryologic coronary implantation [6]. Acquired coronary to pulmonary artery fistulas are most often due to complications after coronary artery bypass surgery (CABG), particularly when the internal mammary artery is used and also after cardiac transplantataion. It may also result after percutaneous coronary interventions (PCI). One of the mechanisms proposed for pathogenesis of the acquired coronary to pulmonary artery fistulas is because of neovascularization under the control of specific organizing proteins. The cause of the coronary fistula in our patient is uncertain because it could be congenital or acquired. Most of the patients are asymptomatic and are usually discovered as incidental findings during cardiac catheterization and are seen on one of every 500 - 1000 coronary angiograms [6]. Congenital CAF are commonly associated with obstructive coronary artery disease. Patient is usually asymptomatic. Patient may present with symptoms such as fatigue and dyspnea. Cardiomyopathy, congestive heart failure, atrial fibrillation can occur as late findings in cases of coronary artery fistulas [7]. Other complications related to coronary fistulas include myocardial ischemia from a steal phenomenon whereby competitive flow occurs and also from embolization due to thrombus formation within aneurysmal segments. Clinical signs uncommonly found in an adult patient with CAF include a continuous murmur heard along the left sternal border and cardiomegaly with enlargement of the right chambers [8]. Location of murmur at the apex and accentuation of the diastolic component are important characteristic findings of coronary artery fistulae. Selection of therapeutic option in fistulas is controversial. If the fistulas are small or does not cause ischemia follow up can be the alternative strategy. If ischemia occurs secondary to fistula or is symptomatic, transcatheter closure of coronary artery fistula or surgery can be the choice for treatment. In appropriate cases, trans-catheter closure can be the alternative to surgery. However, surgical repair may be indicated in cases of coronary artery fistulas with additional complex heart disease which requires surgery. The main indications for closure of CAF are clinical symptoms, particularly heart failure and myocardial ischemia. In asymptomatic patients with highflow shunting closure is done to prevent occurrence of undesirable complications. Surgical intervention is also recommended in patients who are at risk for future complications such as bacterial endocarditis, thrombosis, 
distal embolization, aneurysm, dissection, rupture, pulmonary hypertension, premature atherosclerosis, myocardial ischemia [9]. Currently, percutaneous treatment is proposed as the first choice because it is less radical and entails a shorter period of hospitalization [10]. Surgery is reserved for cases of multiple fistulae, those affecting large branches during embolization of coils, or when the fistulous connection is narrow, restrictive and draining into a cardiac chamber [11]. Our patient presented with inferior wall myocardial infarction with significant lesions in LAD, LCX and along with dual coronary artery fistula originating from distal part of left anterior descending artery and proximal part of right coronary artery. Patient was taken for coronary artery bypass grafting followed by ligation of fistula.

\section{References}

[1] Levin, D.C., Fellows, K.E. and Abrams, H.L. (1978) Hemodynamically Significant Primary Anomalies of the Coronary Arteries. Circulation, 58, 25. http://dx.doi.org/10.1161/01.CIR.58.1.25

[2] Schamroth, C. (2009) Coronary Artery Fistula. Journal of the American College of Cardiology, 53, 523. http://dx.doi.org/10.1016/j.jacc.2008.06.055

[3] Jerbi, S., Tarmiz, A., Fradi, S., et al. (2009) Coronary Artery Fistula: Case Report and Review of the Literature. Annales de Cardiologie et $d$ Angéiologie (Paris), 58, 236-239. http://dx.doi.org/10.1016/j.ancard.2008.05.014

[4] Urrutia-S, C.O., Falaschi, G., Ott, D.A. and Cooley, D.A. (1983) Surgical Management of 56 Patients with Congenital Coronary Artery Fistulas. Annals of Thoracic Surgery, 35, 300-307. http://dx.doi.org/10.1016/S0003-4975(10)61563-9

[5] Lerberg, D.B., Ogden, J.A., Zuberbuhler, J.R. and Bahnson, H.T. (1979) Anomalous Origin of the Right Coronary Artery from the Pulmonary Artery. Annals of Thoracic Surgery, 27, 87. http://dx.doi.org/10.1016/S0003-4975(10)62981-5

[6] Yamanaka, O. and Hobbs, R.E. (1990) Coronary Artery Anomalies in 126,595 Patients Undergoing Coronary Arteriography. Catheterization and Cardiovascular Diagnosis, 21, 28-40. http://dx.doi.org/10.1002/ccd.1810210110

[7] Perloff, J.K. (1994) Congenital Coronary Artery Fistula. In: Perloff, J.K., Ed., The Clinical Recognition of Congenital Heart Disease, Saunders, Philadelphia, 562-580.

[8] Parga, J.R., Ikari, N.M., Bustamante, L.N., Rochitte, C.E., de Avila, L.F. and Oliveira, S.A. (2004) Case Report: MRI Evaluation of Congenital Coronary Artery Fistulas. The British Journal of Radiology, 77, 508-511. http://dx.doi.org/10.1259/bjr/24835123

[9] Luo, L., Kebede, S., Wu, S. and Stouffer, G.A. (2006) Coronary Artery Fistulae. American Journal of the Medical Sciences, 332, 79-84. http://dx.doi.org/10.1097/00000441-200608000-00005

[10] Cheng, T.O. (1999) Management of Coronary Artery Fistulas: Percutaneous Transcatheter Embolization versus Surgical Closure. Catheterization and Cardiovascular Interventions, 46, 151-152. http://dx.doi.org/10.1002/(SICI)1522-726X(199902)46:2<151::AID-CCD7>3.0.CO;2-G

[11] Mavroudis, C., Backer, C.L., Rocchini, A.P., Muster, A.J. and Gevitz, M. (1997) Coronary Artery Fistulas in Infants and Children: A Surgical Review and Discussion of Coil Embolization. Annals of Thoracic Surgery, 63, 1235-1242. http://dx.doi.org/10.1016/S0003-4975(97)00251-8

\section{Abbreviations}

CAF, Coronary Artery Fistulas;

LAD, Left Anterior Descending;

LCA, Left Circumflex Artery;

RCA, Right Coronary Artery;

STEMI, ST-Elevation Myocardial Infarction;

CABG, Coronary Artery Bypass Surgery. 
Submit or recommend next manuscript to OALib Journal and we will provide best service for you:

- Publication frequency: Monthly

- 9 subject areas of science, technology and medicine

- Fair and rigorous peer-review system

- Fast publication process

- Article promotion in various social networking sites (LinkedIn, Facebook, Twitter, etc.)

- Maximum dissemination of your research work

Submit Your Paper Online: Click Here to Submit

Contact Us: service@oalib.com 